Article

\title{
Discourses of Roma Anti-Discrimination in Reports on Human Rights Violations
}

\author{
Chloë Delcour ${ }^{1,2, *}$ and Lesley Hustinx ${ }^{2}$ \\ ${ }^{1}$ Research Foundation-Flanders, 1000 Brussels, Belgium \\ ${ }^{2}$ Sociology Department, Ghent University, 9000 Ghent, Belgium; E-Mails: chloe.delcour@ugent.be (C.D.), \\ Lesley.hustinx@ugent.be (L.H.) \\ * Corresponding author
}

Submitted: 21 January 2015 | In Revised Form: 29 April 2015 | Accepted: 6 May 2015 |

Published: 29 September 2015

\begin{abstract}
In an effort to understand the paradox between the expansion of inclusion projects for the Roma and their persisting exclusion, this article explores human rights practice in order to grasp the complexity of meanings of inclusion negotiated in this practice. In this way, we scrutinize whether there are limiting factors within the inclusionary discourse itself. Specifically, we analyze the discourse in transnational judicial, political and civil society actors' reports on violations of human rights against Roma. A strong shared tendency to frame the violations in terms of discrimination can be discerned in the reports, demonstrating a dominant concept in the human rights discourse for Roma. However, a framing analysis of the underlying assumptions of this concept shows that not all three actors offer the same solutions for obtaining non-discrimination, which can partly explain the limited impact of the ostensibly strong and inclusive antidiscrimination discourse. In contrast, the actors do share a negative attribution of responsibility to the nation states, but the effectiveness of this shared discursive claim can be questioned. This article illustrates how inclusion discourses are actually quite complex to grasp and so it substantiates the need for greater critical understanding of such discourses in further research.
\end{abstract}

\section{Keywords}

human rights; Gypsy travellers; inclusion; discourse; discrimination; report; Roma

\section{Issue}

This article is part of the special issue "Talking about Roma: Implications for Social Inclusion", edited by Dr. Eben Friedman (Independent Consultant and Senior Non-resident Research Associate, European Centre for Minority Issues, Germany).

(C) 2015 by the authors; licensee Cogitatio (Lisbon, Portugal). This article is licensed under a Creative Commons Attribution 4.0 International License (CC BY).

\section{Introduction}

From the 1990s onwards, the Roma have been increasingly ethnicized and represented as a homogeneous European minority by European institutions, Romani groups and associations, governmental and nongovernmental organizations, scholars and various media (Van Baar, 2008). Moreover, they have been framed as a European minority par excellence. Having no established connection with a kin state which will lobby and advocate on their behalf, it is claimed that
Roma need to rely on European institutions and agreements to get their rights acknowledged. Consequently, the Council of Europe and the EU have gradually set up inclusive measures and projects for the Roma (Sigona \& Vermeersch, 2012). European fora have been mobilized and European institutions and civil society have become increasingly alert to human rights violations for Roma.

However, Roma are also still continuously confronted with such human rights violations across multiple European countries (Bancroft, 2005; Pogány, 
2012; Sigona \& Vermeersch, 2012). Ideas about the Roma are submerged in multiple negative stereotypes and exclusionary logics. Apparently, these constructions are not overcome by the trends towards inclusion. Therefore, there is a need for analysis of the meanings that are created in inclusionary discourses in order to find clues about the limiting factors that hold back these inclusion projects.

An interesting and innovative way to do this is by looking at human rights practices. Although human rights are often perceived as universally accepted standards of inclusion, increasingly more sociologists recognize that it is necessary to understand how and in which contexts human rights cultures are created. Human rights are then perceived as originating, existing and being applied in specific contexts, which can be framed as social struggles (Keck \& Sikkink, 1999; Madsen, 2011; Morris, 2006; Nash, 2009; Waters, 1996; Woodiwiss, 2005). This struggle forms a continuous (re)negotiation of norms and ideas about human rights through discursive framing by different interpretive communities (judicial, political, civil society); groups of actors which have different perspectives on the meaning of human rights (Madsen, 2011; Morris, 2006; Nash, 2009; Waters, 1996; Woodiwiss, 2005). This ambiguity is possible because human rights form an abstract set of norms and values which is open for interpretation. Certain norms or interpretations are therefore prioritized and thus a practical definition of what human rights are-or what they should be-is made, involving definitions of social inclusion. Thus, by looking into human rights practice for Roma, we can gain insight into the inclusionary discourses for this group.

Furthermore, within this human rights practice, we have chosen focus on reports about violations of Roma human rights. The discursive interpretation of human rights involves first determining whether a violation has occurred. When an actor declares a violation has taken place, this entails a definition of what human rights are or should be. Consequently, reports on human rights violations form an interesting part of human rights practice. Despite its importance, no research can be found on this topic.

Hence, this article analyzes reports on human rights violations for Roma and Gypsy travellers prepared by significant transnational judicial, political and civil society actors, the European Court of Human Rights, the Council of Europe Commissioner for Human Rights and the European Roma Rights Centre, respectively. This analysis first shows that the reports share a strong focus on the concept of (non-)discrimination. However, a framing analysis shows that this concept is not linked to a shared strict legal definition but instead entails different discursive interpretations for every actor, which can partly help to explain why discrimination practices have not yet been addressed in a consistent and effective way.

\section{Theoretical Framework: Inclusion for Whom, by Whom, and How It Needs to Be Reached}

Our theoretical framework is based on an analysis of Roma inclusion policy in the critical Romani studies tradition, which gives insight in to the question of for whom, by whom and how Roma inclusion is being envisioned. These dimensions will be used to analyze reports about violations in the results section and will thus enable us to unravel some meanings attached to human rights and Roma inclusion.

\subsection{Who Is Included? Roma as the European Minority "Par Excellence"}

From the 1990s onwards, European institutions and Romani civil society have argued that Roma and Gypsy people can be seen as a European minority "par excellence" (Van Baar, 2008; Vermeersch, 2012). Having no established connection with a kin state which will lobby and advocate on their behalf, it is claimed that Roma need to rely on European institutions and agreements to get their rights acknowledged. As a consequence, Europe has gradually developed a specific Roma-related policy focused on inclusion and integration (for example, the European Platform for Roma inclusion and the Decade for Roma Inclusion) (Sigona \& Vermeersch, 2012).

However, Romani studies have shown that this promising policy also produces some important side effects. First, the fight for recognition of Roma brought forth an essentializing dynamic, representing Roma as a homogeneous minority (Hemelsoet, 2013; IgnatoiuSora, 2011; McGarry, 2011; Tremlett, 2009a; Van Baar, 2008; Vermeersch, 2012). Consequently, although it is clear that there are vast differences between Roma groups, they are neglected. Roma who cannot identify with the new European Roma identity and its accompanying norms cannot, therefore, benefit from European-led inclusion.

Secondly, Romani studies have warned that the Roma-focused inclusion policy can produce the opposite effect. Holding the identity of an excluded European minority reconfirms the outsider character of the group and reinforces the boundary which separates them from the integrated mainstream group (Gay y Blasco, 2008; Goodwin, 2009; Hemelsoet, 2013; McGarry, 2011; Van Baar, 2008; Vermeersch, 2012). Although this confirmation of exclusion is not necessarily deliberately generated, it can be employed by rightist and racist groups to emphasize the different character of the Roma and to blame them for creating their own problems.

\subsection{How to Attain Inclusion? Roma as Holders of Individual Rights, a Socio-Economically Excluded Group or a Cultural Minority}

An important characteristic of the inclusion discourse 
which has appeared in Romani studies literature is how the object of inclusion policy is conceptualized. These studies show that Roma can be framed in three different ways, leading to a different inclusion strategy and thus different outcomes. These different approaches are not exclusive, they share certain characteristics while differing in other aspects (this is summarized in Figure 1). Furthermore, the different approaches reflect a certain evolution in thinking about inclusion of the Roma minority, where throughout time different organizations and institutions have chosen to emphasize or neglect certain approaches/dimensions.

\subsubsection{Roma as Holders of Individual Rights (Individual Rights)}

The framework that was strongly used by Romani movements in the 1990s (such as the ERRC) and then picked up by judicial and political institutions was based on the ideas of equality and individual human rights (Rövid, 2011). This means that Roma are seen as human individuals, just as equal as other human beings. Therefore, they hold human rights, which are vio- lated when Roma are discriminated against and deprived of things like personal documents, freedom of choice, secure housing, qualitative education, etc. In this perspective, Roma are not described as a group, but violations are evaluated in individual cases and their particular circumstances. This perspective stems from the idea that the target group approach causes a homogenization effect and unintentionally confirms the excluded character of the group (Hemelsoet, 2013).

However, this perspective has been criticized because it leaves a lot of responsibility in the hands of nation states, where nation states are given broad competences to protect the human rights of their Roma citizens, enshrined in the constitutions and Council of Europe legislation (O'Nions, 2011). When they don't succeed, there is still no real transnational body which can address such violations in a decisive and consistent manner (Faist, 2001; Isin \& Turner, 2002; Nash, 2009). Therefore, there seems to be a consensus today in literature and in policy that the individual-rights-based approach is inadequate to attain the full inclusion of Roma in society (Rövid, 2011).

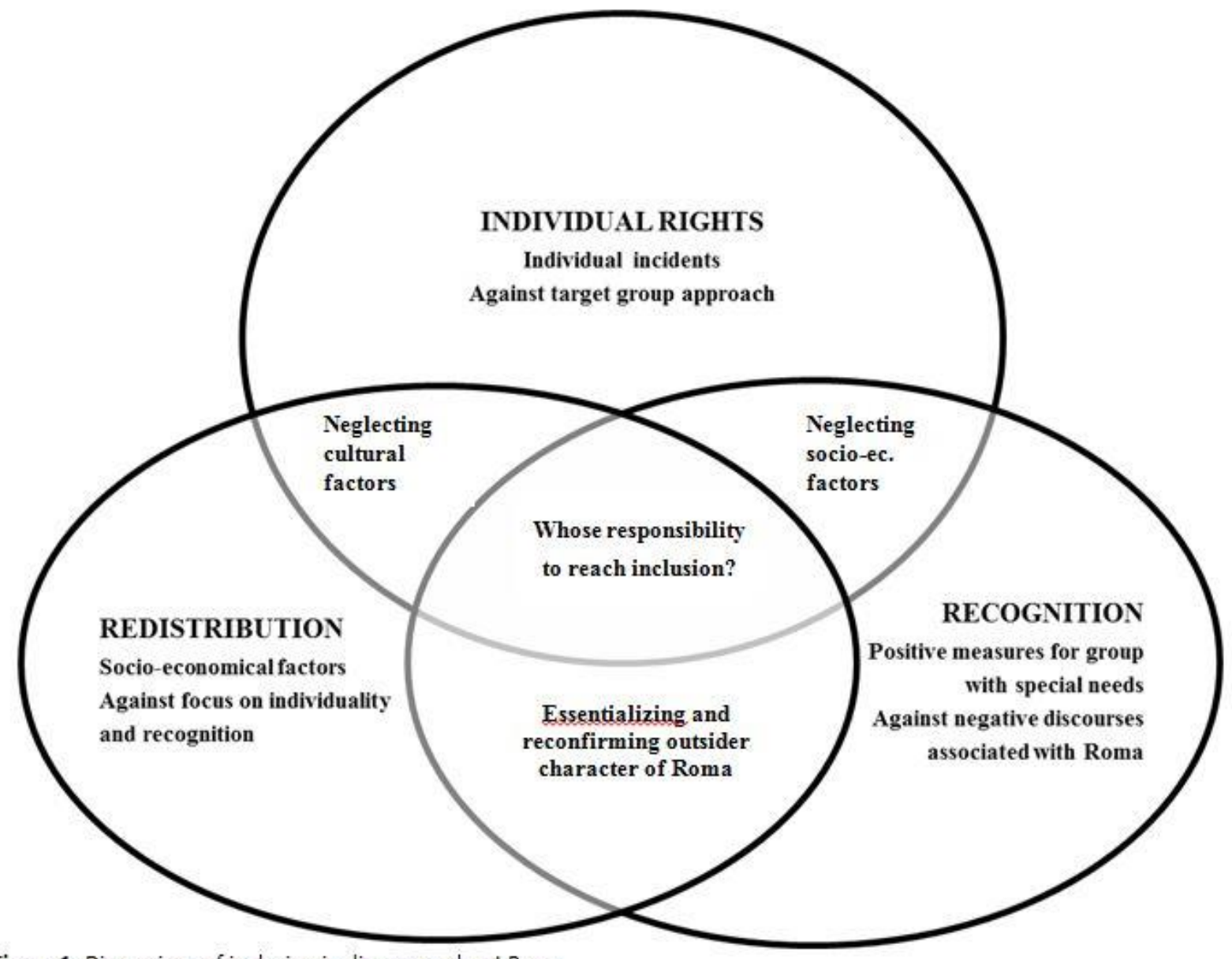

Figure 1. Dimensions of inclusion in discourse about Roma 


\subsubsection{Roma as a Socio-Economically Excluded Group} (Redistribution)

Another criticism levelled against the individual rights approach that is increasingly emphasized is the observation that the focus on individuality neglects the fact that Roma are confronted with a strongly disadvantaged socio-economic structural situation (IgnatoiuSora, 2011; O'Nions, 2011; Rövid, 2011). According to this approach, which has received widespread support in recent years, Roma are targeted as a group that has primarily socio-economic interests because of severe deprivation, which intensified after the fall of communism. This approach is clearly reflected in EU institutions, who see EU funding (such as the European Social Fund and the European Agricultural Fund for Rural Development) as a key instrument in addressing the socio-economic deprivation of Roma. It is argued that the situation of the Roma is complex, and thus other societal factors besides racial discrimination need to be addressed, such as poverty rates, absence of public transportation in Roma neighbourhoods, poor health conditions because of living circumstances, etc. In its communication about the EU Framework for National Roma Integration Strategies, the European Commission (2011) clearly frames the improvement of the situation of the Roma as a social and economic imperative. Specifically, they focus on needs regarding equal access to employment, education, housing and healthcare.

Similar to the individual rights approach is the cultural minority perspective (see below), which is criticized for overemphasizing recognition and commemoration of the Roma group while underemphasizing the socio-economical character of their deprivation (McGarry, 2011; Rövid, 2011; Tremlett, 2009b; Van Baar, 2008; Vermeersch, 2012). This shared neglect of socio-economic factors in the individual rights and recognition approaches is shown on the right hand side of Figure 1. However, the socio-economic program is in its turn criticized for ignoring the impact of discrimination, while this can lead to a disturbed employment of financial means allocated, certainly on the local level (Rövid, 2013). Furthermore, in these socio-economically focused policies Roma are constantly identified with misery, unemployment, uncivilized living circumstances, lack of schooling, etc. This leads to a strong stigmatization, which reconfirms the existing stereotypes and frames Roma as a socially burdensome group.

\subsubsection{Roma as Cultural Minority (Recognition)}

In addition to the approaches above, the Roma can also be framed as a cultural minority. Although this approach is still only rarely applied to the Roma minority, it is the most common way to deal with the rights of national minorities; to identify them as a separate group with special needs and to take positive measures to assure these needs are fulfilled (McGarry, 2012; O'Nions, 2011; Rövid, 2011). The focus on individual racial discrimination and socio-economic redistribution neglects the fact that Roma are a cultural minority which deserves recognition, which could in turn lead to special measures to improve their situation (see left part of Figure 1). Furthermore, as was discussed above, the individual rights and socio-economic approaches identify the Roma only with negative cases and frames, while this approach seeks to highlight the positive character of Romani cultural identity and therefore its need for preservation and development (Ignatoiu-Sora, 2011). This approach is increasingly employed during initiatives such as International Roma Day, in which different civil society organizations (such as the European Roma Information Office (ERIO)) are involved and take the opportunity to celebrate Roma culture, tradition, and identity and its contribution to European societies. They claim that Romani literature, music and art, together with Romani traditions, language and history form an integral part of European heritage, and that recognition of this can lead to empowerment and also to social inclusion of Roma (ERIO, 8 April 2015).

However, we should note that this approach is difficult to align with the nation-state model, which explains the persistent resistance against recognition of minorities (McGarry, 2012; Rövid, 2011). Furthermore, just as for the socio-economic perspective, this approach could also intensify the division between Roma and non-Roma, as great emphasis is placed on the different ethnic character of the group (this shared characteristic is shown in the centre of Figure 1). As this ethnic group is still severely deprived, they have a limited capacity to deal with problems using their ethnic shared interests.

To conclude, it can be said that the problems Roma are facing are a complex set of racial discrimination, socio-economic issues and minority claims, and thus ask for an integrated approach (Rövid, 2011; Tremlett, 2009b; Van Baar, 2008; Vermeersch, 2012). In the results section, we evaluate which inclusion dimensions the three selected transnational actors emphasize, and which-if any-attempt to combine all three dimensions in a comprehensive Roma inclusion approach.

\subsection{Whose Responsibility Is It to Attain Inclusion?}

Another important aspect discussed in globalization and Roma inclusion policy studies concerns the role of nation states in protecting the individual rights of its citizens and in providing redistribution and recognition for the Roma group (Nash, 2009; O'Nions, 2011; Rövid, 2011; Sassen, 2007; Tremlett, 2009b). Thus, this issue can be linked to all three inclusion perspectives (individual rights, redistribution, recognition), as can be seen in Figure 1. Because of the transnational character of human rights and the European guiding of Roma in- 
clusion policy, a tension arises between the "new" responsibilities of supranational institutions and the "traditional" responsibilities of the nation states towards their citizens. For example, nation states with an anti-Romani agenda try to minimize or evade their responsibility towards the Roma by stating that because of the European character of this minority, the European Union is responsible for its integration (Rövid, 2011). But, although Europe proactively stimulates and coordinates the Roma inclusion policy, it still heavily depends on nation states to keep on investing in inclusive actions. This illustrates how human rights and inclusion of Roma people are actually a responsibility of both nation states and (different) supranational institutions, yet the specific balance and division of responsibilities is often a result of a continuous (discursive) power struggle between specific actors. Below we will assess which constructions are made in this respect by different transnational actors.

\section{Analysis and Methods}

\subsection{Step 1: Overall View of the Discourse of Reports on Violations}

As a first step in our analysis, the goal was to get an overall view of the discourse of reports about human rights violations against Roma and Gypsy travellers in a mix of West-European migration countries and Centraland East-European countries (where the Roma have been established for a longer time). Therefore, we set up a cross-national ${ }^{1}$ inventory of reported human rights violations from the 1990s until 2012, using judgements and reports from a transnational ${ }^{2}$ political, a judicial and a civil society actor.

Local and national political actors influence the human rights discourse by approving and implementing human rights law (Nash, 2009). Transnational political actors often take the form of intergovernmental institutions, bringing together national political actors on the human rights issue. In Europe, the Council of Europe ( $\mathrm{COE})$ is the longest established institution in this category. The Commissioner for Human Rights (CECHR) forms an independent institution within the Council and provides advice and information on the prevention of human rights violations and releases opinions, issue papers and reports (CoE, 2014a). One of the recent reports (Commissioner of Europe, 2012) presents the

\footnotetext{
${ }^{1}$ Italy, France, Czech Republic, Slovakia, Romania and Bulgaria were included.

${ }^{2}$ It should be noted that we do not want to suggest that national and local actors do not take an important role in the discursive argument concerning human rights. However, we choose to focus on transnational actors because this paper focuses on the reporting practice which predominantly occurs at a transnational level.
}

first overview of the (present and past) human rights situation of Roma and Travellers, covering all 47 member states of the Council of Europe (CoE, 2014b). Although strictly speaking the CECHR is an independent institution and although the report was prepared by a multitude of academic, intergovernmental and civil society professionals, its symbolic value derives from the fact that the report was published with the support of the Council of Europe and is recognized as such by public opinion. Therefore, we used this document to analyze political human rights discourse.

Judicial actors are also important with regard to human rights discourse because judges have a strong interpreting power in the underdeveloped and contentious field of human rights law (Nash, 2009). For this analysis, we looked at the past judgements of Roma human rights cases at the European Court of Human Rights (ECHR). ${ }^{3}$ The ECHR makes judgements on the basis of the European Convention of Human Rights (CoE, 4 November 1950) and is one of the primary sources of human rights jurisdiction in Europe, embedded in the Council of Europe. This focus and thus the exclusion of the Court of Justice of the European Union is legitimized by the longer and more established tradition of the Council in protecting the human rights of Roma.

Finally, civil society plays an important role in putting pressure on other actors to live up to and extend the human rights system (Nash, 2009). One of their strategies in this regard is judgement- and eventsbased reporting about human rights, implying that they report about violations based on human observation of single violating events, which provide a more extensive and lively overview (United Nations Human Rights Office of the High Commissioner, 2012). One of the leading international NGO's striving for Roma inclusion, the European Roma Rights Centre (ERRC), looks upon its public exposure and condemnation of the systemic abuse of Roma rights across Europe as one of its major achievements (ERRC, 2012; Goodwin, 2009; IgnatoiuSora, 2011). Its extensive research programme has produced a reliable database on the human rights situation of Roma, which we searched for every selected country (starting from 1990 until 2012) in order to analyze the human rights discourse of the civil society actor.

It should be noted that the ERRC has consultative status with the Council of Europe and thus also has a strong link with the Council, like the Court and the Commissioner. Thus, it can be stated that all three selected actors take a prominent role in reporting about Roma and their human rights, as enshrined in Council of Europe law. Furthermore, these three institutions are interacting in important ways. First, the ERRC has lodged numerous cases against European countries

\footnotetext{
${ }^{3}$ We used a recent factsheet summarizing the past judgements of the ECHR on Roma and Travellers cases (ECHR, June 2012) to start our analysis.
} 
with the European Court of Human Rights, by representing the applicants (ERRC, 2015). Moreover, they have pursued multiple third party interventions in the Court's cases. Second, the Council of Europe Commissioner for Human Rights similarly engages with the Court, as he also has the right to intervene in pending cases on his own initiative (Muižnieks, 26-27 March 2015). But the Commissioner also takes on a complementary task: he looks at the broader context beyond the legal aspects of the case and tries to prevent legislative proposals that would violate the Convention and he assists governments in addressing the systemic problems causing the violations. Lastly, the Commissioner and the ERRC are primarily linked through indirect cooperation: they both refer to each other's expertise in their reports and comments (Commissioner of Europe, 2015).

This paper limits its focus to these three institutions engaged with Council of Europe law and thus excludes European Union institutions ${ }^{4}$ as this enables us to suppose that all three actors are talking about the same package of human rights when reporting about violations and thus differences in their approach could not be explained by a different guiding document. This would not be the case if the European Commission were included, for example, as its discourse would be based on the EU Charter of Fundamental Rights. Instead, the aim of this paper is to understand how different kinds of actors interpret the same law (differently) and in this way attach to it specific meanings of inclusion when reporting about human rights violations for Roma.

\subsection{Step 2: Uncovering Assumptions of the Anti-Discrimination Frame}

After the first step, a second analysis was accomplished in order to better understand the underlying assump-

\footnotetext{
${ }^{4}$ However, these institutions have set up important initiatives for Roma inclusion, such as the EU Framework for National Roma Integration Strategies (in which member states make a strong commitment to design and present their strategy or specific policy measures for Roma inclusion to the European Commission) and the European Roma Platform (bringing together national governments, the EU, international organizations and Roma civil society representatives to stimulate cooperation and exchanges of experience on successful Roma inclusion) (European Commission, 2014). Moreover, the European Parliament, which played a prevalent role in stimulating the Commission to develop the EU Framework, adopted multiple resolutions promoting Roma inclusion, showing their commitment to the issue. Furthermore, the European Union Fundamental Rights Agency (FRA) is a strong partner of the European Commission through their research activities on Roma issues. We do not want to neglect these institutions and suggest that it would be very fruitful to analyze their approaches towards Roma inclusion and compare them with the findings of this paper in further research.
}

tions of the identified anti-discrimination frame. More specifically, we pursued a framing analysis, focusing on the concept and meaning of discrimination. For ECHR and CECHR, we again used past judgements (again starting from the factsheet (ECHR, June 2012)) and the overview report (Commissioner of Europe, 2012) (both the factsheet and the report were published in 2012). ${ }^{5}$ For the ERRC, a framing analysis of all the reports found in the database for the six countries would have been too extensive, so instead we used the four newsletters published by ERRC in 2012 (ERRC, March 2012; June 2012; September 2012; December 2012), supposing these accurately reflect their most recent interpretation of the discrimination concept. ${ }^{6}$

Specifically, the framing analysis tries to grasp the hidden premises behind a certain frame by asking what features of the situation are highlighted or neglected and which kind of prescription for action is implied (Bacchi, 2010; Rein \& Schön, 1993). So in the second step of the analysis, we posed the following questions: Which meanings are attached to the discursive focus on discrimination? Which are highlighted and which potential meanings are neglected? Which implications do these meanings have? Which kind of actions are prescribed to be taken against discrimination? Applying these questions, and guided by the inclusion dimensions discussed above in the theoretical framework, we iteratively coded the judgements/reports. Using these codes, we unravelled the non-discrimination frame for every actor, which enabled us to see similarities and differences and in this way to draw conclusions about the strength and scope of the anti-discrimination focus within the discourse on Roma human rights.

\section{Results}

\subsection{Strong Focus on Discrimination in Reports on Violations}

Despite the fact that all three actors under study are linked to the Council of Europe, they are considered distinct because of the different field (judicial, political, civil society) they belong to. Therefore, we expected to find some kind of discursive differences in their reports, which would reflect differentiated approaches towards Roma inclusion based on their competences and interests as a judicial, political or civil society actor. However, no notable differences could be found and discrimination (superficially known to be prohibited by Council of Europe law, but more broadly defined than

\footnotetext{
${ }^{5}$ In the second step, we dropped the country selection.

${ }^{6}$ This means that the time periods for which we analyzed the discrimination focus in the second step differ between the ECHR and the CECHR (the factsheet and the report covering a period from the 1990s until 2012) and ERRC (only the newsletters from the year 2012).
} 
in purely legal terms) was the common denominator in which all three actors often framed Roma rights violations. The perception seems to prevail that what connects everyone within the Roma group is the experience of racism and discrimination (Goodwin, 2009; Ignatoiu-Sora, 2011): "In the end, the fact that the Roma are historically and structurally subjected to discrimination and racism may appear to be their most defining characteristic from which the multiple social problems flow." (Hemelsoet, 2013, p. 67). This is what Bacchi calls a specific problematization, which implies a discursive problem-setting technique (Bacchi, 2010; Rein \& Schön, 1993). This is not to say that this discrimination is only discursive and not real, but it does show how the different actors involved focused on this discrimination concept as a key symbol in order to see the complex and precarious situation of the Roma through an orderly frame.

The actors evaluated the concerned practices as "systematic", "abusive", "disproportionate", "biased", "corrupt", "arbitrary", "without objective and reasonable justification", etc. Strong condemnation was pronounced for practices such as "segregation", "racial profiling", "negative stereotyping", "anti-Gypsism", "the Holocaust", etc. Roma were referred to as a "vulnerable" and "disadvantaged" group of a "different ethnic background" with "particularities", which national authorities have the "positive obligation" to take into account. These terms illustrate the frequent reference to terms which the different actors associated with discrimination in their discursive interpretation.

The legal literature describing this discrimination focus shows that the legal notion of discrimination is generally almost absent from legal texts and case law issued by the ECHR and the EU before the 1990s (Goodwin, 2009; Ignatoiu-Sora, 2011). From the 1990s, a general but also more specific shift occurs in describing the situation of Roma, and accordingly legal tools were designed to protect Roma from discrimination. This shift in the legal discourse on Roma cases can be explained by an increased interest in the situation of Roma because of the fall of communism and the subsequent political transformations and new migration waves and refugee flows towards Western Europe. Furthermore, the enlargement of the EU and the concern for a stable and secure region raised minority awareness. Also, there was a growing European movement that fought against discrimination, which was legally supported by the establishment of the Racial Equality Directive. Lastly, pro-Romani NGO's-led by the ERRC - stimulated a new discourse focused on human rights and anti-discrimination (Goodwin, 2009; Ignatoiu-Sora, 2011; Rövid, 2011).

Although this historical frame and the fact that all three institutions are linked to the Council of Europe helps to understand the focus on discrimination in the reports of all three actors, two concerns convinced us to go beyond this result and analyze the underlying assumptions of this anti-discrimination frame:

- The different character of the actors implies that they have different interests. For example, the Court is bound by its specific competences, while civil society will try to push the boundaries towards inclusion. If the different actors still employ the same discourse, this means that they are probably being guided by specific strategic considerations. Fox and Vermeersch (2010) frame this through the political opportunity structure theory, which postulates that actors will employ certain discourses according to the opportunities that occur, but always guided by their own logic and interests. So, although there were good general reasons to engage an anti-discrimination frame as was discussed above, this does not mean that all actors were aligned on a deeper level. Therefore, in the second step of the analysis, we aimed to uncover their potentially different logics.

- Although anti-discrimination discourse is used in a very convincing way, a significant change in practice still remains absent (Goodwin, 2009; IgnatoiuSora, 2011). Furthermore, the discourse similarly entails essentializing and stereotyping/stigmatizing side effects, as was discussed for the framing of Roma as a true European minority (Goodwin, 2009; Hemelsoet, 2013; Ignatoiu-Sora, 2011; Peroni \& Timmer, 2013). In fact, Roma are represented as one group, a true European minority, which is continuously confronted with discrimination and thus remains excluded from mainstream society. To understand this low or even negative impact of the anti-discrimination discourse, we need to uncover its underlying assumptions.

\subsection{Incoherent Frames Regarding How to Attain Non-Discrimination}

For the anti-discrimination frame of the three transnational actors, we uncovered an implied prescription for action, and thus, in this case, the means to attain inclusion. In the reports of the three actors, we could distinguish all three perspectives-individual human rights, redistribution and recognition-as possible assumptions underlying the anti-discrimination focus. However, every actor highlights and neglects different assumptions.

It cannot be denied that the ECHR has recently taken up a strong stance against discrimination, prohibited through article 14 of the Convention. An important turning point can be situated in the D.H. case, whereby the Grand Chamber accepted in 2007 that the statistical evidence provided by the applicants was sufficient to give rise to a presumption of indirect discrimination and judged it as an article 14 violation as it did not regard the Czech government's justification as objective 
and reasonable (Dembour, 2009; ECHR, 13 November 2007, § 185-204; Ignatoiu-Sora, 2011; O'Connell, 2009; Smith \& O'Connell, 2011). Moreover, the Court provided a broad definition of what racial discrimination entails, including in it discrimination on account of one's actual or perceived ethnicity and condemned this as a particularly invidious kind of discrimination which requires special vigilance and a vigorous reaction (ECHR, 13 November 2007, § 176; Möschel, 2012). Furthermore, the Court has noticed in several cases that the Gypsy way of life needs to be facilitated and that the Roma constitute a disadvantaged and vulnerable minority group in need of protection (ECHR, 18 January 2001a, § 107, 18 January 2001b, § 96, 18 January 2001c, § 110, 18 January 2001d, § 98, 27 May 2004, § 84, 13 November 2007, § 182, 8 December 2009, § 61, 16 March 2010, § 147, 8 November 2011, § 146, 179, 24 April 2012, § 129-130; Peroni \& Timmer, 2013; Smith \& O'Connell, 2011).

However, this progressive and group-focused approach is a very recent evolution and only seems to apply for certain rights and in cases where a strong consensus exists among the member states, leading to an inconsistent and unpredictable case law. For example, education was established in the ECHR case law as a right (enshrined in article 2 of Protocol no. 1 (CoE, 20 March 1952)) for which Roma are in need of special protection (ECHR, 13 November 2007, 5 June 2008, 16 March 2010). Yet we could not identify any other intentions to relate discrimination practices to the socioeconomic circumstances of the Roma, which also accords with the formal absence of socio-economic rights in the European Convention. In the remaining cases, the Court seems to apply a more formalistic and rigorous logic, assessing every case individually. In a number of these cases, the Court is still cautious to judge a violation of article 14, requiring proof beyond reasonable doubt or deciding the case purely through analysis of the other right invoked together with article $14^{7}$, causing article 14 to remain underdeveloped in ECHR case law (Dembour, 2009; ECHR, 29 September 1996, § 88, 18 May 2000, § 94, 18 January 2001a, § 132, 18 january 2001b, § 129, 18 January 2001c, § 141, 18 January 2001d, § 129, 18 January 2001e, § 138, 20 July 2004, § 77, 6 July 2005, § 147-159, 13 December 2005, § 65-68,

\footnotetext{
7 To clarify, article 14 always needs to be invoked in conjunction with another allegedly violated right. The Convention only prohibits discrimination for the rights and freedoms set forth in the Convention (as opposed to Protocol $n^{\circ} 12$, which holds a general prohibition of discrimination, but which was only ratified by 17 of the 47 member states). This in itself shows a cautious design of the scope of article 14, limiting the competence of the Court. However, more importantly, even where article 14 applies, an analysis of this article is often dismissed once a violation of the other concerned article has been decided upon. This means that the Court is not applying its-already limited-competence to its full extent.
}

26 July 2007a, § 93-95; Möschel, 2012; O'Connell, 2009; Smith \& O'Connell, 2011). These cases often concern racial violence by the police or evictions, while cases of discrimination regarding classic civic-political rights, such as the right to a fair trial or investigation ${ }^{8}$ or the right to stand for election, get more easily judged as discriminatory and thus violating article 14 (ECHR, 6 July 2005, 12 July 2005, 13 December 2005, 31 May 2007, 26 July 2007a, 26 July 2007b, 6 December 2007, 22 December 2009, 25 March 2010, Möschel, 2012, O'Connell, 2009).

In conclusion, we can state that the ECHR remains cautious in addressing discrimination as described in the Convention, only having a clear established view in evaluating individual cases of discrimination concerning classic civic-political rights. It should be noted that our focus on the ECHR can give a somewhat distorted image, as there are other judicial or quasi-judicial institutions with different competences that do take on a stronger anti-discrimination discourse. In particular, the European Committee of Social Rights has proven to be more progressive, for example in terms of the right to housing (Möschel, 2012). In a way this difference in approach is evident, as the ECHR relies on the European Convention of Human Rights, which has a traditional civic-political rights focus (and the prohibition of discrimination only applies to the rights set forth in the Convention), while the European Social Charter that guides the European Committee of Social Rights is built around socio-economic rights. However, this does not explain why the Court did make progress in cases concerning education but not racial violence (while one is protected against violence by the classical right to life and prohibition of torture enshrined in article 2 and 3 of the Convention (CoE, 4 November 1950)), which also suggests that progress is in fact possible (but until now very limited) with regard to socio-economic rights. Competence is thus an important factor to take into account when analyzing the Court's approach, but it does not account for everything. To conclude, as the ECHR is seen to be one of the most important judicial bodies in our current global society, its reserved attitude is worth paying attention to.

In comparison to the ECHR, the Commissioner for Human Rights of the Council of Europe takes a far more integrated approach: "The human rights situation of Roma and Travellers should be addressed as a whole and different fields addressed simultaneously" (Commissioner of Europe, 2012, p. 222). The report pays attention to discrimination regarding a variety of civic and political rights guaranteed through Council of Eu-

\footnotetext{
8 In fact, the judgements on the violation of this right often concern the failure of authorities to investigate the possible racist motives behind the mentioned racial violence cases. So these cases do get a judgement of a procedural violation of article 14 , but no substantive violations are found by the Court.
} 
rope law (such as racially motivated violence, unfair treatment by law enforcement and judicial authorities, forced sterilization, lack of personal identification documents, obstructed participation in public life and decision-making processes), but also broadly covers the socio-economic situation of the Roma (with regard to education, housing, employment, health, social security and access to goods, services and public places) in which racial discrimination is seen as one of the determining factors (Commissioner of Europe, 2012). For example, segregated education is described as being influenced by racist attitudes of non-Roma parents who send their children to predominantly white schools, but also by the socio-economic context of segregated neighbourhoods. Furthermore, the report also points at times to the need for special protection, which implies that states need to take special measures (such as teaching about Romani language, culture and history or recognition of mass atrocities against the Roma via truth commissions) in order to take the distinct character of the Roma community into account.

Lastly, the European Roma Rights Centre takes a firm approach in emphasizing discrimination as a violation of human rights of individual Roma, but also acknowledges the effect on their socio-economic resources (ERRC, March 2012, June 2012, September 2012, December 2012). For example, it will elaborate on the multiple effects of a forced eviction or lack of personal documents on housing conditions, access to work, education, healthcare and other services. However, recognition and the framing of Roma as a culturally distinct group in need of special protection measures seem to be absent in their anti-discrimination discourse.

To conclude, it is clear that the prescriptions for action behind the anti-discrimination frame are not aligned across the three different actors. Despite the interlinkage between the three institutions expressed in a shared superficial focus on discrimination, we thus found that there are important differences in the underlying meanings of this focus. In a sense, this is normal, as all three actors have different characters and thus also different competences. For example, it is more natural for the Commissioner to take an integrated approach as he can get an overview of multiple national situations, while the Court is bound to look only at individual cases. However, this issue of competence should not obscure the fact that these differences in the non-discrimination discourse do exist, as they can maybe help to explain why discriminatory practices have not yet been addressed in a consistent and effective way. Although all actors analyzed seemingly use the same frame embedded in Council of Europe law, this only entails a shallow alignment, in which every actor is highlighting different meanings and dimensions. For example, although the ERRC proudly states that "through its strategic litigation and landmark cases the ERRC has contributed the devel- opment of the Court's jurisprudence regarding Article 14 of the European Convention on Human Rights" (ERRC, 2015), we argue that this jurisprudence is still quite limited, inhibiting a truly coherent approach of discrimination.

Subsequent analysis (of discourse outside of the reports, of specific measures aimed at eliminating discrimination and their implementation in practice, and of the interaction and cooperation between the three institutions) is needed to understand the precise implications of this incoherent approach within the Council of Europe's institutions. We suggest that the lack of synchronization can partly explain the limited impact of the anti-discrimination approach in human rights discourse on the lives of Roma and Gypsy Travellers. Further research is required in order to grasp the detailed specifics of and a full explanation for this limited impact. In conclusion, it would be interesting to critically analyze the anti-discrimination approach of EU institutions, to scrutinize whether they are more aligned on this issue and to compare their emphasized meanings and prescriptions with those found in this paper.

\subsection{Accusing the Nation States}

Another premise that clearly came to the fore in looking at the anti-discrimination frame of all three actors is the shared conviction that ultimately nation states are responsible for protecting the Roma residing on their territories (Commissioner of Europe, 2012; ERRC, March 2012, June 2012, September 2012, December 2012; ECHR, June 2012). This can be seen as a subjectification process (Bacchi, 2010), where nation states are created as the responsible parties in the human rights story of the Roma. This is predominantly a negative discourse, pointing to what nation states must do or didn't succeed in doing to protect Roma against discrimination: "The Commissioner calls on the governments of Europe to intensify and deepen their efforts to ensure that Roma finally enjoy equal dignity in societies free of discrimination" (Commissioner of Europe, 2012, p. 224).

Again, competence can partly explain this shared focus on the responsibility of nation states, as only the Council of Europe member states have the competence to take tangible measures towards non-discrimination as premised by the Council. Furthermore, the public nature of the reports issued by ERRC and the Commissioner implies that the victims and the global public expect them to clearly attribute responsibility. However, these explanations for a negative view of nation states should not impede its critical analysis. This article doubts the effectiveness of the focus on national responsibility, as transnational actors fail to take into account the complex responsibilities for some situations where nation states often have difficulties in impelling their local authorities to respect human rights. Furthermore, we suggest it only instigates more re- 
sistance from nation states, a continuous shifting of responsibility, and an intensified opposition towards the Roma. Although globalization theories increasingly emphasize that globalization is a hybrid, cooperative project in which multiple actors play a crucial role (Nash, 2009; Sassen, 2007), transnational actors seem to emphasize the old oppositional idea of the global versus the national in their human rights discourse. Further research analyzing the human rights discourse of national actors could provide more insight in their response towards this discourse and thus in the discursive power struggle between transnational and national actors on the allocation of responsibility to create Roma inclusion.

\section{Conclusion}

In an effort to understand the paradox between the expansion of inclusion projects for the Roma and their persisting exclusion, this article explored human rights practices in order to grasp the complexity of meanings of inclusion negotiated in this practice. In this way, we scrutinized whether there were limiting factors within the inclusionary discourse itself. Specifically, we analyzed the discourse in reports on violations of human rights against Roma which were prepared by a transnational judicial, a political and a civil society actor. Discerning in their reports a strong shared tendency to frame the violations in terms of discrimination, we identified a dominant concept in human rights discourse for Roma. This has important implications as it means Roma are constantly associated with these discrimination practices. This runs the risk of essentializing and stereotyping the Roma as one group unified by the experience of discrimination which causes them to live "on the margins of society". Moreover, as this antidiscrimination frame only has a limited impact, we can question whether this frame is really a helpful instrument on the path towards inclusion.

Furthermore, an analysis of the underlying assumptions of the anti-discrimination frame showed that not all three actors share the same prescriptions for attaining non-discrimination, while they do share a negative attribution of responsibility to nation states. With these results, we were able to show how the seemingly coherent inclusionary discourse of transnational actors on Roma human rights can actually entail multiple meanings and specific premises. This illustrates how the inclusion trend is actually more complex to grasp and so this substantiates the need for greater critical understanding of the deeper meanings of this inclusion discourse in further research. These incoherent deeper meanings partly help to explain why discriminatory practices have not yet been addressed in a consistent and effective way. It is of course only a small aspect in providing an answer to this question, but it does show the importance of taking a critical look at inclusionary approaches, which are often simply assumed to be the best solutions. Certainly for the Roma, there seem to exist some "popular" ideas about their inclusion the strength of which remains limited in practice (for example, anti-discrimination, the notion of Roma being victims, Roma empowerment, local participation, etc.). Perhaps these ideas are not convincingly shared by all the involved actors on a deeper level of meaning, or perhaps they have specific limiting assumptions, and thus a critical analysis of the discourses that carry these ideas is necessary.

Furthermore, this analysis contributes to human rights research, providing a rare empirical example of discursive ambiguity in terms of human rights and illustrating its complex character. Moreover, the discourse studied in this article was taken from the reports on human rights violations. Although reports are seen to be reflections of reality rather than steered discourse, we showed that these reports do inform us about definitions of human rights and inclusion from different actors and are thus an important part of human rights discursive contestation which should not be neglected.

\section{Acknowledgements}

Chloë Delcour is a PhD fellow of the Research Foundation-Flanders. We would furthermore like to thank the anonymous reviewers of this journal for their constructive and helpful comments. Moreover, we would like to thank Sarah Ganty, Ph.D. student at Université Libre de Bruxelles working in migrant and human rights law, and her supervisors Prof. Dr. Emmanuelle Bribosia and Prof. Dr. Isabelle Rorive for their very useful remarks on the legal analysis. Finally, we thank the undergraduate sociology students who participated in the data collection in the academic year 2012-2013.

\section{Conflict of Interests}

The authors declare no conflict of interests.

\section{References}

Bacchi, C. (2010). Foucault, policy and rule: Challenging the problem-solving paradigm (FREIA-Feminist Research Center in Aalborg paper, June). Aalborg: Aalborg University.

Bancroft, A. (2005). Roma and Gypsy-travellers in Europe: Modernity, race, space and exclusion. Aldershot: Ashgate.

Commissioner of Europe. (2012). Human rights of Roma and Travellers in Europe. Strasbourg: Council of Europe Publishing.

Commissioner of Europe. (2015). Mandate. Website. Retrieved from http://www.coe.int/en/web/ commissioner/mandate

Council of Europe (CoE). (4 November 1950). European 
Convention for the Protection of Human Rights and Fundamental Freedoms, as amended by protocols No. 11 and 14. ETS 5. Strasbourg: Council of Europe Publishing.

CoE. (20 March 1952). Protocol to the Convention for the Protection of Human Rights and Fundamental freedoms, as amended by Protocol No. 11. ETS 009. Strasbourg: Council of Europe Publishing.

CoE. (2014a). Commissioner for Human Rights. Website. Retrieved from http://www.coe.int/en/web/ commissioner/mandate

CoE. (2014b). Human Rights of Roma and Travellers. Website. Retrieved from http://www.coe.int/en/ web/commissioner/thematic-work/roma-andtravellers

Dembour, M. B. (2009). Still silencing the racism suffered by migrants.... The limits of current developments under Article 14 ECHR. European Journal of Migration and Law, 11, 221-234.

ERRC. (2012). Who we are. Website. Retrieved from http://www.errc.org/about-us-overview

ERRC. (2015). Strategic litigation: European Court of Human Rights. Website. Retrieved from http://www.errc.org/strategic-litigation-europeancourt-of-human-rights

ERRC. (March 2012). Violence against Roma on the rise: ERRC testifies. ERRC News, 15.

ERRC. (June 2012). ERRC acts to ensure safety and adequate conditions for Serbia's Belvil evictees. ERRC News, 16.

ERRC. (September 2012). France evictions and expulsions, ERRC helps more than 2000 Roma. ERRC News, 17.

ERRC. (December 2012). Continued injustice for Roma in Czech Republic. ERRC News, 18.

European Commission. (2011). Communication from the Commission to the European Parliament, the Council, the European Economic and Social Committee and the Committee of the Regions. An EU Framework for National Roma Integration Strategies up to 2020 (173/4). Brussels: European Commission.

European Commission. (2014). Tackling discrimination: EU and Roma. Website. Retrieved from http://ec.euro pa.eu/justice/discrimination/roma/index_en.htm

European Court of Human Rights (ECHR), Chamber. (29 September 1996). Buckley v. The United Kingdom. Appl. No. 20348/92.

ECHR, $4^{\text {th }}$ sect. (18 May 2000). Velikova v. Bulgaria. Appl. No. 41488/98 (final since 4 October 2000).

ECHR, Grand Chamber. (18 January 2001a). Beard v. The United Kingdom. Appl. No. 24882/94.

ECHR, Grand Chamber. (18 january 2001b). Chapman v. the United Kingdom. Appl. No. 27238/95.

ECHR, Grand Chamber. (18 January 2001c). Coster v. The United Kingdom. Appl. No. 24876/94.

ECHR, Grand Chamber. (18 January 2001d). Lee v. The
United Kingdom. Appl. No. 25289/94.

ECHR, Grand Chamber. (18 January 2001e). Jane Smith v. The United Kingdom. Appl. No. 25154/94.

ECHR, $1^{\text {st }}$ sect. (27 May 2004). Connors v. The United Kingdom. Appl. No. 66746/01 (final since 27 August 2004).

ECHR, 2nd sect. (20 July 2004). Balogh v. Hungary. Appl. No. 47940/99 (final since 20 October 2004).

ECHR, Grand Chamber. (6 July 2005). Nachova and Others v. Bulgaria. Appl. Nos. 43577/98 and 43579/98

ECHR, $2^{\text {nd }}$ sect. (12 July 2005). Moldovan and Others v. Romania. Appl. Nos. 41138/98 and 64320/01 (final since 30 November 2005).

ECHR, $4^{\text {th }}$ sect. (13 December 2005). Bekos and Koutropoulos v. Greece. Appl. No. 15250/02 (final since 13 March 2006).

ECHR, $1^{\text {st }}$ sect. (31 May 2007). Secic v. Croatia. Appl. No. 40116/02 (final since 31 August 2007).

ECHR, $3^{\text {rd }}$ sect. (26 July 2007a). Cobzaru v. Romania. Appl. No. 48254/99 (final since 26 october 2007).

ECHR, $5^{\text {th }}$ sect. (26 July 2007b). Angelova and lliev $v$. Bulgaria. Appl. No. 55523/00 (final since 26 October 2007).

ECHR, Grand Chamber (13 November 2007). D. H. and Others v. The Czech Republic. Appl. No. 57325/00.

ECHR, $1^{\text {st }}$ sect. (6 December 2007). PetropoulouTsakiris v. Greece. Appl. No. 44803/04 (final since 6 March 2008).

ECHR, $1^{\text {st }}$ sect. (5 June 2008). Sampanis and Others $v$. Greece. Appl. No. 32526/05 (final since 5 September 2008).

ECHR, $3^{\text {rd }}$ sect. (8 December 2009). Munoz Díaz v. Spain. Appl. No. 49151/07 (final since 8 March 2010).

ECHR, Grand Chamber. (22 December 2009). Sejdic and Finci v. Bosnia and Herzegovina. Appl. Nos. 27996/06 and 34836/06.

ECHR, Grand Chamber. (16 March 2010). Orsus and Others v. Croatia. Appl. No. 15766/03.

ECHR, $5^{\text {th }}$ sect. (25 March 2010). Paraskeva Todorova $v$. Bulgaria. Appl. No. 37193/07 (final since 25 June 2010).

ECHR, $4^{\text {th }}$ sect. (8 November 2011). V.C. v. Slovakia. Appl. No. 18968/07 (final since 8 February 2012).

ECHR, $4^{\text {th }}$ sect. (24 April 2012). Yordanova and Others v. Bulgaria. Appl. No. 25446/06 (final since 24 September 2012).

ECHR (June 2012). Factsheet-Roma and Travellers. ECHR: Press Unit.

European Roma Information Office. (8 April 2015). Press release: Celebrating Roma culture and history as a part of European heritage. Retrieved from http://www.erionet.eu/doc-press-releaseinternational-roma-day_2015

Faist, T. (2001). Social citizenship in the European Union: Nested membership. Journal of Common Mar- 
ket Studies, 39(1), 37-58.

Fox, J. E., \& Vermeersch, P. (2010). Backdoor nationalism. European Journal of Sociology, 51(2), 325-357.

Gay y Blasco, P. (2008). Picturing "Gypsies": Interdisciplinary approaches to Roma representation. Third Text, 22(3), 297-303.

Goodwin, M. (2009). Multi-dimensional exclusion: viewing Romani marginalization through the nexus of race and poverty. In D. Schiek \& V. Chege (Eds.), European Union non-discrimination law: Comparative perspectives on multi-dimensional equality law (pp. 137-162). Abingdon: Routledge.

Hemelsoet, E. (2013). The Roma people: problem or mirror for Western European societies? An exploration of educational possibilities. In M. Miskovic (Ed.), Roma education in Europe: Practices, policies and politics (pp. 59-70). Philadelphia: Routledge.

Ignatoiu-Sora, E. (2011). The discrimination discourse in relation to the Roma: Its limits and benefits. Ethnic and Racial Studies, 34(10), 1697-1714.

Isin, E. F., \& Turner, B. S. (2002). Handbook of citizenship studies. London: Sage.

Keck, M. E. \& Sikkink, K. (1999). Transnational advocacy networks in international and regional politics. International Social Science Journal, 51(1), 89-101.

Madsen, M. R. (2011). Reflexivity and the construction of the international object: The case of human rights. International Political Sociology, 5(3), 259275.

McGarry, A. (2011). The Roma voice in the European Union: Between national belonging and transnational identity. Social Movement Studies, Journal of Social, Cultural and Political Protest, 10(3), 283-297.

McGarry, A. (2012). The dilemma of the European Union's Roma policy. Critical Social Policy, 32, 26-36.

Morris, L. (Ed.) (2006). Rights: Sociological perspectives. London: Routledge.

Möschel, M. (2012). Is the European Court of Human Rights' case law on anti-Roma violence "beyond reasonable doubt"? Human Rights Law Review, 12(3), 479-507.

Muižnieks, N. (26-27 March 2015). Intervention by Council of Europe Commissioner for Human Rights in the High-level Conference on the "Implementation of the European Convention on Human Rights: our shared responsibility". Retrieved from https://wcd.coe.int/com.instranet.InstraServlet?com mand=com.instranet. $C m d B l o b G e t \& I n s t r a n e t / m a g e=$ 2717230\&SecMode $=1 \&$ Docld $=2253368$ \& Usage $=2$

Nash, K. (2009). The cultural politics of human rights: comparing the US and UK. Cambridge: Cambridge University Press.

O'Connell, R. (2009). Cinderella comes to the Ball: Article 14 and the right to non-discrimination in the ECHR. Legal Studies: The Journal of the Society of Legal Scholars, 29(2), 211-229.

O'Nions, H. (2011). Roma expulsions and discrimina- tion: The elephant in Brussels. European Journal of Migration and Law, 13(4), 361-388.

Peroni, L., \& Timmer, A. (2013). Vulnerable groups: The promise of an emerging concept in European Human Rights Convention Law. International Journal of Constitutional Law, 11(4), 1056-1085.

Pogány, I. (2012). Pariah peoples: Roma and the multiple failures of law in Central and Eastern Europe. Social and Legal Studies, 21(3), 375-393.

Rein, M., \& Schön, D. A. (1993). Reframing policy discourse. In F. Fischer \& J. Forester (Eds.), The argumentative turn in policy analysis and planning (pp. 145-166). Durham, NC: Duke University Press.

Rövid, M. (2011). One-size-fits-all Roma? On the normative dilemmas of the emerging European Roma policy. Romani Studies, 21(1), 1-22.

Rövid, M. (2013). Roma Rights 2012: Challenges of representation: Voice on Roma politics, power and participation. Website. Retrieved from http://www. errc.org/en-research-and-advocacy-romadetails.php?article_id $=4174 \&$ page $=1$

Sassen, S. (2007). Sociology of globalization (1st ed.). New York: W.W. Norton.

Sigona, N., \& Vermeersch, P. (2012). The Roma in the new EU: Policies, frames and everyday experiences: introduction. Journal of Ethnic and Migration Studies, 38(8), 1189-1193.

Smith, A., \& O'Connell, R. (2011). Transition, equality and non-discrimination. In A. Buyse \& M. Hamilton (Eds.), Transitional jurisprudence and the European Convention on Human Rights (pp. 185-207). New York: Cambridge University Press.

Tremlett, A. (2009a). Bringing hybridity to heterogeneity in Romani studies. Romani Studies, 19(2), $147-$ 168.

Tremlett, A. (2009b). Comparing European institutional and Hungarian approaches to Roma (Gypsy) minorities. In T. Agarin \& M. Brosig (Eds.), Minority integration: Debating ethnic diversity in Eastern Europe (pp. 129-150). Amsterdam: Rodopi.

United Nations Human Rights Office of the High Commissioner. (2012). Human rights indicators: A guide to measurement and implementation. New York \& Geneva: United Nations.

Van Baar, H. (2008). The way out of amnesia? Europeanisation and the recognition of the Roma's past and present. Third Text, 22(3), 373-385.

Vermeersch, P. (2012). Reframing the Roma: EU Initiatives and the Politics of Reinterpretation. Journal of Ethnic and Migration Studies, 38(8), 1195-1212.

Waters, M. (1996). Human rights and the universalisation of interests: Towards a social constructionist approach. Sociology, the Journal of the British Sociological Association, 30(3), 593-600.

Woodiwiss, A. (2005). Human rights. Abingdon: Routledge. 


\section{About the Authors}

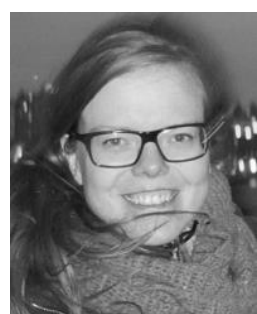

\section{Chloë Delcour}

Chloë Delcour obtained her Master in Sociology (2010-2011) at Ghent University. Her thesis was awarded the 2010-2011 Marthe Versichelen Prize for the best master thesis in sociology. She currently works as a PhD fellow of the Research Foundation-Flanders at the Department of Sociology at Ghent University. She is a member of the Centre for Social Theory and of the research group POS+ (Participation, Opportunities, Structures). Her doctoral research is situated within the interdisciplinary domains of political sociology and sociology of human rights.

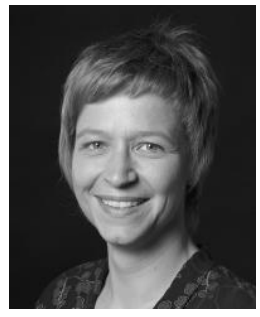

\section{Dr. Lesley Hustinx}

Lesley Hustinx is associate professor at the Department of Sociology at Ghent University. She is a member of the Centre for Social Theory and of the research group POS+ (Participation, Opportunities, Structures). Her major research interests include societies in transition, and the consequences of recent social change for the condition and nature of citizenship and citizen-based solidarity. 